\title{
Use of production functions in assessing the profitability of shares of insurance companies
}

\author{
Raed Ali Alkhasawneh, Ahmed Mohamed Farhan Mohamed, Samir Abdulwahab Jaradat, \\ M. Sh. Torky, Mutasem K. Alsmadi \\ College of Applied Studies and Community Service, Imam Abdulrahman Bin Faisal University, Dammam, Saudi Arabia
}

\begin{tabular}{l}
\hline \hline Article Info \\
\hline Article history: \\
Received Oct 12, 2019 \\
Revised Jul 12, 2020 \\
Accepted Nov 4, 2020
\end{tabular}

\section{Keywords:}

Cobb-Douglas production function

Cointegration test Insurance companies' profitability Transcendental production function

Unit root test

Zener-Rivanker production function

\section{Corresponding Author:}

Raed Ali Alkhasawneh

Department of General Courses

Imam Abdulrahman Bin Faisal University

P. O. Box 1982, Dammam, 31441, KSA, Saudi Arabia

Email: ralkhasawneh@iau.edu.sa

\begin{abstract}
In this study the production functions (Cobb-Douglas, Zener-Rivanker, and the transcendental production function) have been used to assess the profitability of insurance companies, by reformulating these nonlinear functions based on the introduction of a set of variables that contribute to increase the explanatory capacity of the model. Then the best production function commensurate with the nature of the variable representing the profitability of insurance companies was chosen, to use it to assess the efficiency of their profitability versus the use of different factors of production and thus the possibility of using it in forecasting. It was found that the proposed model of the production function "Zener-Rivanker" is the best production functions representing the profitability of the Tawuniya and Bupa Insurance Companies. The proposed model of the Cobb-Douglas production function is suitable for the results of both Enaya and Sanad Cooperative Insurance Companies. The explanatory capacity of the production functions was also increased when the proposed variables were added (net subscribed premiums-net claims incurred).
\end{abstract}

This is an open access article under the CC BY-SA license.

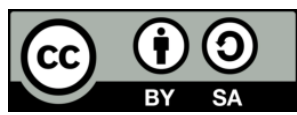

\section{INTRODUCTION}

Many of the insurance companies operating in Saudi Arabia succeeded in transferring their losses during 2017 to profits that exceeded the expected limits during the year 2018, according to the reports of the Saudi Monetary Agency. This improvement is due to the control imposed by the Saudi Arabian Monetary Agency (SAMA) on the insurance sector in the kingdom. The existence of a series of irregularities that have emerged from the insurance norms because of the intense competition among insurance companies in the market in an effort to gain more market share. It contributed in increasing the risk of underwriting, that is reflected in the sudden increase in the profits of these companies, which resulted from a rise in net subscribed insurance premiums for the sector as a whole by $56 \%$ in 2018 , despite the increase of net claims incurred by $45 \%$, as well as the increase of public and administrative expenses by $60 \%$ and the cost of underwriting insurance policies increased by 12\% (The Saudi Arabian Monetary Agency (SAMA)). It provides sufficient evidence for insurers to accept further risks without considering the risk of reverse choice in exchange for a larger market share. This has necessitated the development of a range of effective tools to assess the profitability of insurance companies. The study of the efficiency of the production functions in assessing the profitability of the insurance company has acquired great importance lately. The main benefit of using 
production functions is to reach estimates of the flexibility of production elements, which include both work and capital, and the impact of these variables on the evaluation of the profitability of insurance companies. This leads to more growth in the insurance sector.

\section{LITERATURE REVIEW}

The study of production functions has occupied a large part of the interest of many researchers in the economic field, due to the importance of the results of this analysis in the recognition of the extent of the contribution of production elements to the profitability of the enterprise, which enables it to predict accurately the profitability of the enterprise in the future, and below is a presentation of the most important Studies dealing with this topic:

Early work in [1], the authors choose and estimate the parameters of Cobb-Douglas function with additive errors and multiplicative errors for some selected manufacturing industries of Bangladesh over the period 1978-1979 to 2011-2012, which should be helpful in suggesting the most suitable Cobb-Douglas production function to forecast the production process for some selected manufacturing industries of developing countries like Bangladesh. While the study in [2] test the application of the Cobb-Douglas production function reliability for the Czech economy to analyze the supply-side performance and measurement of a country's productive potential. He applied a more general form of production function and allow labor share to develop according to the empirical data. For the period 1995-2005, he did not find significant difference between the calculation of the supply side of the Czech economy by the Cobb-Douglas production function and a more general production function.

Measuring the productivity function and scale of economies for small and medium sized enterprises in transition countries respectively in Albania and Macedonia was examined in [3]. He estimates an equivalent linear function of logarithms of Cobb Douglas production function. The resulting estimated coefficients of the Cobb-Douglas production function are output elasticities of respective inputs and in our estimation output elasticity of capital is 0.46 and output elasticity of labor is 0.78 .

The researchers in [4] try to estimate Cobb-Douglas and CES production functions in traditional way. They use capital and labor services instead of capital stock and labor. Then they came to conclusion that to get statistically sound results when elasticities equal factor shares, it is necessary to use the latter approach to deal with the factor's utilization. However, doing so revealed that such modified estimate is only an estimate of income identity in disguise as predicted by the critique.

The production function in the tourism sector in the Arab Republic of Egypt, using the CobbDouglas production function, as well as studying the possibility of substitution between the components of production in the tourism sector was examined in [5]. Their study concludes that production yields in the tourism sector The Egyptian is a fixed-volume yield, as the total flexibility of production for independent elements has reached a true one. While the work in [6], try to use the production function to obtain a relationship between agricultural inputs and walnut yield in view of energy inputs, and to make an economic analysis in walnut (Juglans regia) orchards in Hamedan, Iran. Econometric analysis results revealed that human labor, farmyard manure, chemical fertilizers, water for irrigation and transformation contributed significantly to the yield. The results of the sensitivity analysis of the energy inputs showed that the marginal physical productivity (MPP) value of human labor was the highest, followed by farmyard manure and water for irrigation energy inputs, respectively. The benefit to cost ratio, mean net return and productivity from walnut production was obtained as $2.1,2043.7 \$$ ha- 1 and $0.3 \mathrm{~kg} \$-1$, respectively.

In their study in [7], the researchers try to test empirically the Cobb-Douglas production function for manufacturing sector of Bangladesh. Data of the total value of output, total asset, total liabilities, number of permanent workers etc. of about six major types of industries including Garments, Textiles, Food and Food Processing, Leather and Leather Products, Electronics and Chemicals and Pharmaceuticals have been used. Researchers use the total value of output as Y, total liabilities as $\mathrm{K}$, and number of permanent workers (including official's managers, personal) as L. Study finds that coefficient for K and L are 0.49 and 0.51 respectively for the entire manufacturing sector. In case of Garments, coefficient for $\mathrm{K}$ is 0.30 and $\mathrm{L}$ is 0.61 implying that labor is more productive than capital. The statement is also true for Textile sector and Leather and leather products. Capital is, on the other hand, more productive than labor in Food and food processing industries, Electronics, Chemicals and Pharmaceuticals sectors. Findings reveal that Cobb-Douglas production function is applicable and exhibits increasing returns to scale in the context of the manufacturing sector of Bangladesh.

The efficiency of the profitability of insurance companies operating in the European market, as well as the determination of the optimum production limit was examined in [8]. Their study was based on a sample of 175 companies operating in nine European countries during the period from 2002 to 2008, and a function was selected for the Lagrange (Lagrangian Function) which is used to reach the optimum profit level 
for each of the sample companies depending on the market prices for both input and output. The study found that the companies in question have the potential to achieve a greater level of efficiency in profitability by changing their production plans, and that these companies incur additional costs of high operating expenses.

Through a review of previous studies, it may be noted that the estimation of production functions in previous studies did not deviate from the direct application of traditional production functions, and that most of the previous studies relied on the estimation of the production functions at the sectoral level, while the current study relied on the development of production functions, reflecting the contribution of a range of other productive factors to the profitability of insurance companies, as an attempt to formulate a production function representing profitability in the cooperative insurance sector in Saudi Arabia.

\section{RESEARCH LIMITS}

The study in this research is limited to the following limits:

a) Spatial boundaries:

The study dealt with a sample of cooperative insurance companies operating in Saudi Arabia, these companies are (Tawuniya Insurance Company, Bupa Arabia for Cooperative Insurance, Saudi Enaya Cooperative Insurance, Sanad Cooperative Insurance).

b) Time limits:

The research dealt with the quarterly data included in the financial reports of the companies in question during the time period beginning in the first quarter of 2015 and until the end of the fourth quarter of 2018, where the financial reports accompanying this time period were characterized by the existence of complete data and accurate.

c) Production functions:

Three formulas will be tested for production functions (Cobb-Douglas production function, production function for Zener-Rivanker and the Transcendental Production Function), then select the most suitable one to assess the profitability of insurance companies through the use of earnings of the stock to reflect the elements of production, and the social capital of the company to reflect the head element working money, the number of employees in the company to reflect the work component of the production function, and the ability of the variable net subscribed premiums and net claims incurred to increase the explanatory capacity of the production functions was also tested.

\section{THE ECONOMICAL AND MATHEMATICAL NATURE OF PRODUCTION FUNCTIONS}

Production functions are used to measure the contribution of work and capital components to production. It is considered one of the most important instruments of economic analysis, and the interest of economists in production functions has led to a clear breakthrough in the methods of economic analysis [9]. The production functions can be described as a mathematical function used to express a range of relationships achieved by a combination of factors of production as a result of economic activity and take this relationship in its simplest form $Y=f\left(x_{1}, x_{2}, \ldots \ldots, x_{n}\right)$, see [10-13].

Since the Y-factor variable represents productivity, the independent variables $\left(x_{1}, x_{2}, \ldots \ldots x_{n}\right)$ represent factors influencing productivity, which are interrelated and overlapping, but many economists have identified them with three essential elements that are subject to increase according to the nature of the phenomena in question. These factors include both capital size $(k)$, which reflects the volume of physical means available and used to pump production services. As well as the amount of work $(L)$ that represents the flow of production services that come as a result of the work item. In addition to the element of technical progress and renewal, it symbolizes the symbol $(C)[14,15]$. The study and analysis of these functions is based on the omission of the monetary part of the production process, by deleting it from the function, which enables us to deal with a function that includes the quantities of production, and the amount of items involved in the production, without taking into account the price variable resulting from the change of width and demand for various goods and services $[16,17]$.

\section{MAIN TYPES OF PRODUCTION FUNCTIONS}

Cobb-Douglas production function was introduced by both the American economist Paul. $H$. Douglas and the American mathematician COBB. Charles. W., and this function measures the impact of the employment and capital component's contribution to production, and is considered one of the most important tools of economic analysis, which has spread widely especially in the field of economic studies, and this function expresses the economic behavior of the production process, and it depends in its analysis on two factors, namely work and capital $[11,12]$. Leontief production function has evolved for its innovation of the 
input-output table, and the function of Leontief is the simplest form of expression of production functions, reflecting the contribution of inputs to production $[13,16]$. The fixed substitution flexible production function (CES) which produced by the economist arrow and others and it had a fixed replacement elasticity function, a homogeneous non-linear function, and this function represents an alternative to the production function of a CobbDouglas, a homogeneous first-class function. The transcendental production function (TBF) is one of the solutions offered to address the deficiencies that accompanied the application of the Cobb-Douglas production function, in order to conform to the trend of classical theory, which attributed the basic components of productive processes to three elements, namely, work and head money and technology, and are merged with each other to obtain the outputs of goods and services [14-17].

\section{USE OF PRODUCTION FUNCTIONS TO DESCRIBE THE NON-LINEAR RELATIONSHIP OF STUDY VARIABLES}

6.1. Assessing the profitability of insurance companies shares using "the Cobb-Douglas production function"

The researchers reformulated the production function of Cobb-Douglas to suit the nature of the proposed models and the variables in question, and the following Figure 1 illustrates the proposed models of the production function Douglas-Cobb [18-21]. Depending on the EVIEWS 9 statistical program, the parameters of each of the previous nonlinear functions were estimated, using the Hooke Jeeves Pattern Movies method in estimating the unknown parameters, for each of the individual company, the statistical results of each of the companies replaced the study $[22,23]$ are presented in Table 1.

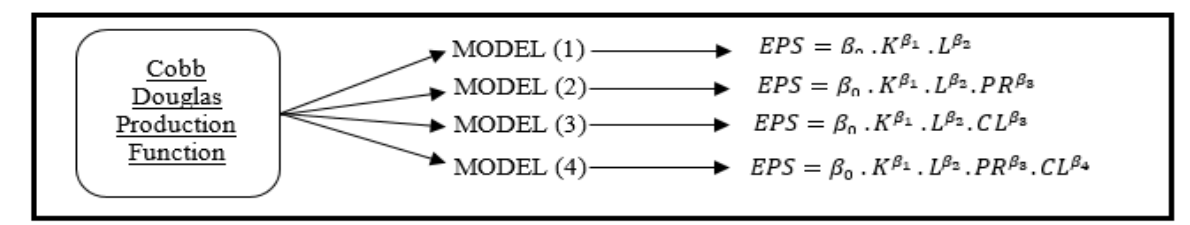

Source: From the numbers of researchers based on the proposed model variants of the Douglas Cobb function

Figure 1. Illustrates the proposed models for assessing stock profitability using the glass Douglas production function*

Table 1. Shows the statistical results of assessing the profitability of shares of the company in the study using Suggested models for Cobb-Douglas production function*

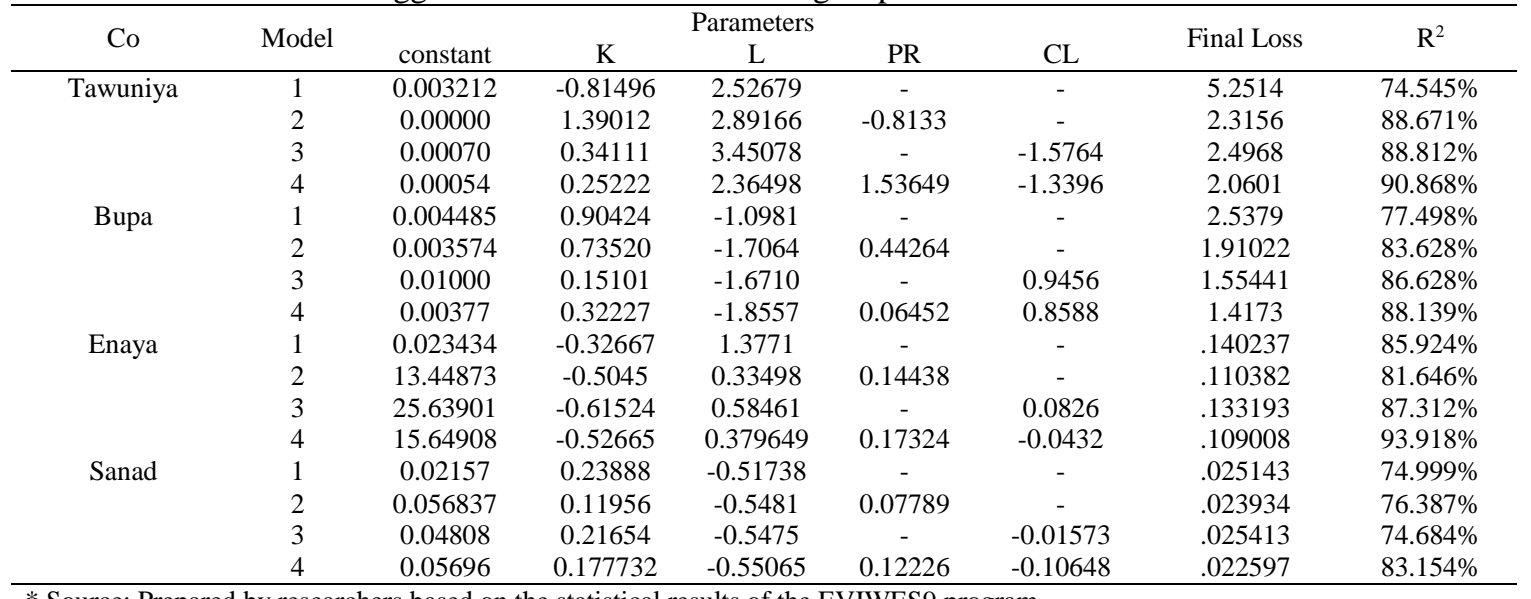

* Source: Prepared by researchers based on the statistical results of the EVIWES9 program.

\subsubsection{Tawuniya Insurance Company}

From the previous table, the fourth proposed model represents the most explanation for the change in the values of the variable of the company in question, with the model's determining factor of $90.868 \%$. Thus, if work and capital explain the change in equity profitability by $74.545 \%$ as in the first model, the entry of the variable representing the subscribed shares contributed to the increase of the selection coefficient to $88.671 \%$. While the addition of the variable claims incurred increased the interpretation factor to $88.812 \%$, 
the addition of both variables (claims incurred) resulted in an increase in the selection coefficient to $90.868 \%$, and final value loss was the lowest value of the fourth model, 2.0601. This enables us to rely on the results of the fourth proposed model in interpreting the relationship between the respective profitability of the company in question and the proposed explanatory variables. The proposed Cobb Douglas product function of the Tawuniya will be on the form of $[13,17,6]$ :

$$
E P S=0.00054 K^{0.25222} L^{2.36498} P R^{1.53649} C L^{-1.3396}
$$

The previous model reflects the existence of a direct moral relationship to both capital and labor and subscribed premiums as production elements with the profitability of the company's shares and is inversely related to the element of the claims incurred, which is consistent with the recognized economic realities. Through the previous relationship, it can be said that the increase of the capital element by $1 \%$ increases the earnings of the share by $0.252 \%$, but the increase of the work element by $1 \%$ increases the earnings of the share by $2.365 \%$, and the increase in the volume of subscribed premiums by $1 \%$ increases the earnings of the share by $1.536 \%$, The increase in the volume of claims incurred by $1 \%$ results in a decrease in earnings per share by $1.340 \%$. The value of the 0.00054 , which represents the other productive factors that affect the earnings of the stock, has reached a negative effect as a result of a lower value than the correct one.

\subsubsection{Bupa Cooperative Insurance Company}

Bupa's findings confirm the quality of the proposed Cobb-Douglas function model, where the fourth proposed model represents the most explanation for the change in the values of the company's variable, the model's determining factor was $88.139 \%$, and the value of final loss is less valuable for the fourth model and is 1.4173. Which confirms the morale of the proposed model, and then the suggested production function of the Douglas proposed for Bupa will be in the form of:

$$
E P S=0.00377 K^{0.32227} L^{-1.8557} P R^{0.06452} C L^{0.8588}
$$

The previous model reflects the existence of a direct moral relationship to both capital and subscribed premiums and claims incurred as production elements with the profitability of the company's shares and is inversely related to the work component. Through the previous relationship, it can be said that the increase of the capital element by $1 \%$ increases the earnings of the share by $0.322 \%$, and the $1 \%$ of the work item results in a decrease in earnings per share by $1.856 \%$, and the increase of net subscribed premiums by $1 \%$ increases the earnings of the share by $0.065 \%$, The increase in the volume of claims incurred by $1 \%$ will increase the earnings of the share by $0.859 \%$. The value of the 0.00377 , which represents the other productive factors that affect the earnings of the stock, has reached a negative effect as a result of a lower value than the correct one.

\subsubsection{Enaya Cooperative Insurance Co.}

The fourth proposed model represents the most explanation for the change in the values of the care insurance company's variable, with the model's determining factor of $93.918 \%$. The final value of loss was the lowest value of the fourth model, 0.109. This confirms the morale of the proposed model, so the proposed Cobb-Douglas production function of Enaya insurance company will be on the form of:

$$
E P S=15.649 K^{-0.52665} L^{0.379649} P R^{0.137} C L^{-0.0432}
$$

The previous model reflects the existence of a direct moral relationship to both the work and the premiums subscribed as production elements with the profitability of the company's shares, as it is inversely related to the elements of capital and claims incurred. It can be said that the increase of the capital element by $1 \%$ leads to a decrease in the earnings of the share by $0.527 \%$, the increase of the work item by $1 \%$ increases the earnings of the share by $0.379 \%$, and the increase in net subscribed premiums by $1 \%$ increases the earnings of the share by $0.173 \%$, and increase the volume Claims incurred by $1 \%$ result in a decrease in earnings per share of $0.043 \%$. The value of the 15.469 , which represents other productive factors that affect the earnings of the stock, has reached a positive effect as a result of increasing its value from the correct one.

\subsubsection{Sanad Cooperative Insurance Company}

The determining factor for the fourth proposed model of the Cobb Douglas function of Sanad Cooperative Insurance Company was $83.2 \%$, which represents the most explanation for the change in the dependent variable, and the final loss value is the lowest value of the fourth form, 0.0226 . This confirms the morale of the proposed model, and therefore the suggested production function of the Cobb-Douglas proposed for Sanad Cooperative Insurance Company will be in the form of: 
$E P S=0.05696 C A^{0.177732} L^{-0.55065} P R^{0.12226} C L^{-0.10648}$

The previous model reflects the existence of a direct moral relationship to both the capital and the premiums subscribed as production elements with the profitability of the company's shares, as it is inversely related to the work elements and the claims incurred. It can be said that the increase of the capital element by $1 \%$ increases the earnings of the share by $0.178 \%$, the increase of the work item by $1 \%$ leads to a decrease of the earnings of the share by $0.551 \%$, and the increase in the volume of subscribed premiums by $1 \%$ increases the earnings of the share by $0.122 \%$, and increase the volume Claims incurred by $1 \%$ result in a decrease in earnings per share of $0.107 \%$. The value of the 0.057 , which represents other productive factors that affect the earnings of the stock, has reached a positive effect as a result of increasing its value from the correct one.

\subsection{Assessing the profitability of insurance companies' shares using the Zener-Rivanker production function}

The researchers rephrased the function to suit the nature of the proposed models and the variables in question, and the following Figure 2 illustrates the proposed models of the Zener-Rivanker production function [12, 24, 25]. Using the Hooke Jeeves Pattern Movies method in estimating unknown parameters, for the company in question, the researchers present the statistical results in Table 2 for each of the companies in this study.

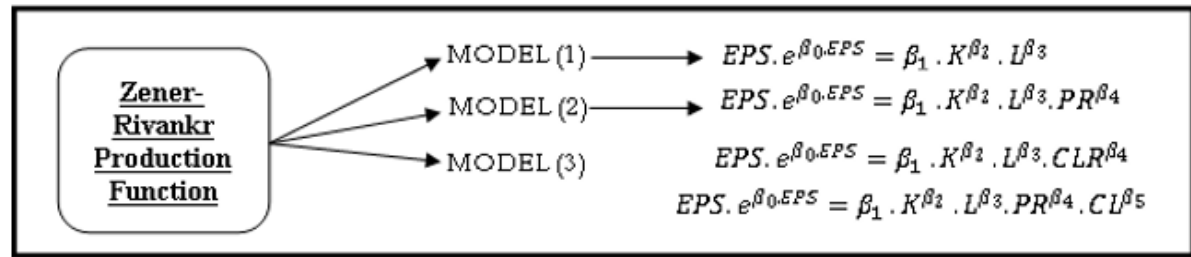

Source: From the numbers of researchers based on the variables of the proposed model of the Zener-Rivanker function

Figure 2. Illustrates the proposed models for assessing the profitability of shares using the Zener-Rivanker production function

Table 2. Shows the statistical results of assessing the profitability of shares of the company using the proposed models of the Zener-Rivanker function*

\begin{tabular}{|c|c|c|c|c|c|c|c|c|c|}
\hline \multirow{2}{*}{ Co } & \multirow{2}{*}{ Model } & \multicolumn{6}{|c|}{ Parameters } & \multirow{2}{*}{ Final Loss } & \multirow{2}{*}{$\mathrm{R}^{2}$} \\
\hline & & constant & K & $\mathrm{L}$ & PR & $\mathrm{CL}$ & $\beta_{0}$ & & \\
\hline \multirow[t]{3}{*}{ Tawuniya } & 1 & 29.9637 & 1.5102 & 1.47337 & - & - & -1.540 & 1.22136 & $95.956 \%$ \\
\hline & 2 & 33.5619 & 1.0078 & 0.7989 & -1.1054 & - & -1.485 & 0.98343 & $96.757 \%$ \\
\hline & 4 & 32.5714 & 0.7561 & 0.6008 & 1.5386 & -0.150 & -1.468 & 0.96102 & $96.832 \%$ \\
\hline \multirow[t]{2}{*}{ Bupa } & 1 & -2.4521 & 0.10000 & 0.1000 & - & - & -0.568 & 0.097 & $98.178 \%$ \\
\hline & 2 & -3.5473 & 0.03829 & 0.2124 & 0.1000 & - & -0.515 & 0.095 & $98.214 \%$ \\
\hline \multirow[t]{4}{*}{ Enaya } & 1 & -4.3013 & 0.6489 & -1.6248 & - & - & -7.6463 & 2.294 & $91.607 \%$ \\
\hline & 2 & -3.1657 & 0.6538 & -1.9799 & 0.1077 & - & -7.0789 & 2.177 & $92.050 \%$ \\
\hline & 3 & 4.3466 & 0.2721 & -2.5472 & - & 0.1225 & -7.2334 & 2.057 & $92.507 \%$ \\
\hline & 4 & -1.556 & 0.5728 & -2.1170 & -0.0121 & 0.1298 & -7.2135 & 2.095 & $92.364 \%$ \\
\hline Sanad & 1 & -10.558 & -0.0096 & 1.1765 & - & - & -21.226 & 8.651 & $80.794 \%$ \\
\hline
\end{tabular}

* Source: Prepared by researchers based on the statistical results of the EVIWES9 program.

\subsubsection{Cooperative Insurance Company}

From the previous table, the fourth proposed model represents the most explanation for the change in the values of the variable of the company in question, where the selection coefficient for the model amounted to $96.832 \%$. The final value of loss was the lowest value of the fourth model, 0.96102 . This enables us to rely on the results of the proposed fourth model in interpreting the relationship between the respective profitability of the company in question and the proposed explanatory variables. Therefore, the proposed production function of the company for the Tawuniya will be in the form of:

$$
E P S . e^{-1.468(E P S)}=32.5714 K^{0.7561} L^{0.6008} P R^{1.5386} C L^{-0.15}
$$




\subsubsection{Bupa Cooperative Insurance Company}

The fourth proposed model represents the most explanation for the change in the values of the company's variable in the study, the model's determining factor was $98.311 \%$, and the final value loss was the lowest value of the fourth form, 0.089. This confirms the morale of the proposed model, so the proposed Zener-Rivanker production function for Bupa will be in the form of:

$$
E P S . e^{-0.641(E P S)}=0.85097 K^{0.00374} L^{-0.7299} P R^{0.1} C L^{0.1}
$$

\subsubsection{Enaya Cooperative Insurance Company}

The third proposed model, which relies on the addition of the variable of claims incurred, represents the most explanation for the change in the values of the care insurance company's variable, with the model's determining factor of $92.507 \%$. The value of final loss also amounted to the lowest value of the third model, 2.057. This confirms the morale of the proposed model, so the proposed Zener-Rivanker production function for Enaya insurance company will be in the form of:

$$
E P S . e^{-7.2334(E P S)}=4.3466 K^{0.2721} L^{-2.5472} C L^{0.1225}
$$

\subsubsection{Sanad Cooperative Insurance Company}

The determining factor for the second proposed form of the Zener-Rivanker function of Sanad Cooperative insurance Company was $83.47 \%$, which represents the most explanation for the change in the dependent variable, and the final loss value is the lowest value of the second form, 7.556. This confirms the morale of the proposed model, so the proposed Zener-Rivanker production function for Sanad Cooperative insurance company will be in the form of:

$$
E P S . e^{-20.015(E P S)}=-11.639 K^{-0.1619} L^{1.3275} P R^{0.1984}
$$

The above is illustrated by the quality of the fourth proposed model of the Zener-Rivanker function of the Tawuniya and Bupa, and the existence of the third proposed model of Enaya and the second proposed form of Sanad Cooperative insurance company, which reflects the positive contribution of both the subscribed premiums and the claims incurred in Increase the interpretation of the change in the dependent variable and the representative in the earnings of the share.

\subsection{Assessing the profitability of the shares of insurance companies using the high production function}

The researchers reformulated the function to suit the nature of the proposed models and the variables, Figure 3 illustrates the proposed models of the transcendental production function $[25,26]$.

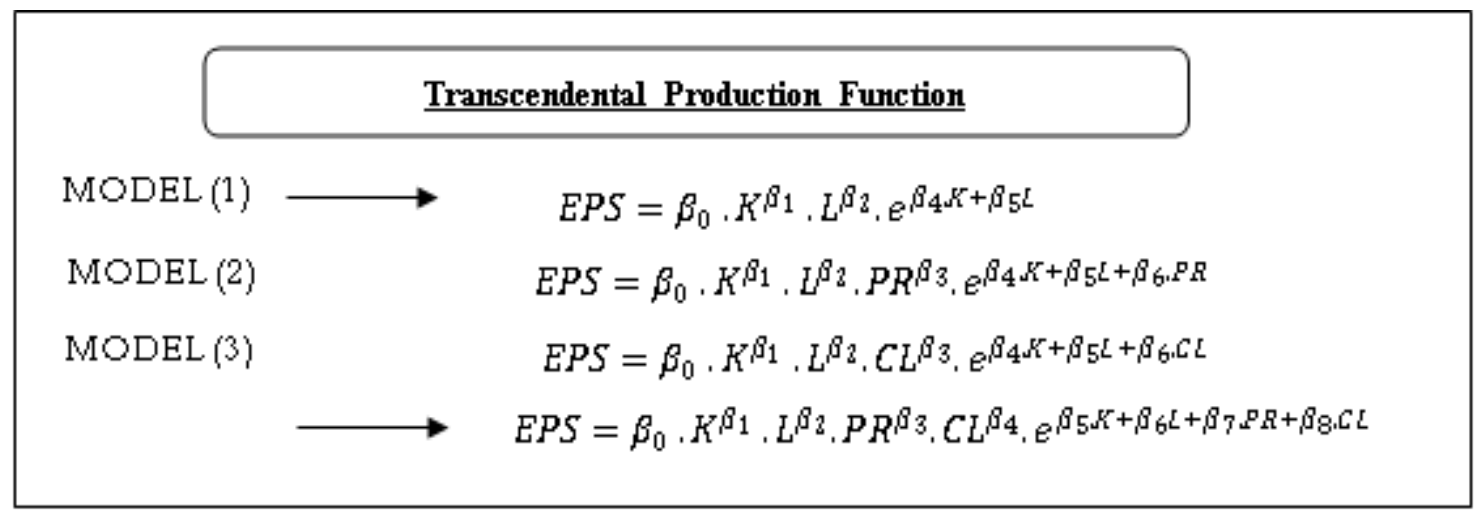

Source: From the numbers of researchers based on the proposed model variables for the transcendental production function

Figure 3. Illustrates the proposed models for assessing the profitability of stocks using a high-yield function

Depending on the statistical program EVIEWS9 the parameters of each of the previous nonlinear functions were estimated using the Quasi-Newton method in estimating the unknown parameters, for the company in question, and the researchers present the statistical results in Table 3 for each of the study companies. 
Table 3. Shows the statistical results of assessing the profitability of the shares of the company using the proposed models of the transcendental production function*

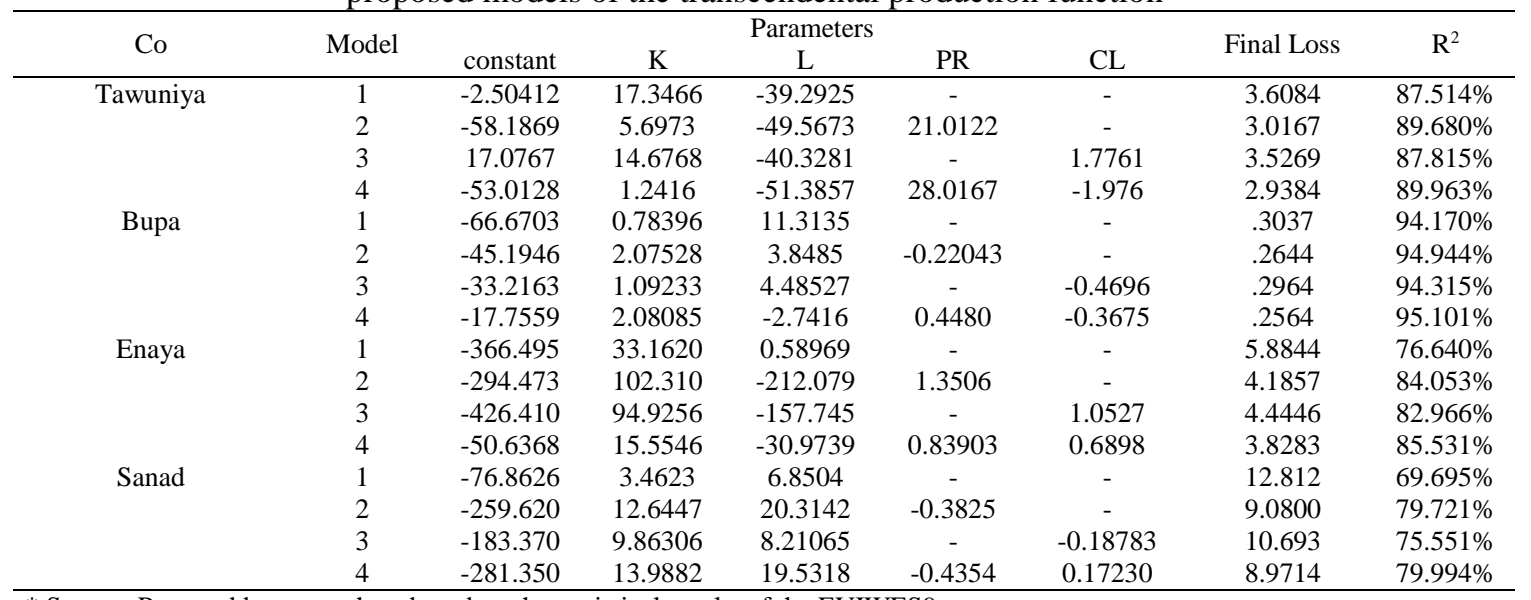

* Source: Prepared by researchers based on the statistical results of the EVIWES9 program.

\subsubsection{Tawuniya Insurance Company}

From the previous table, the fourth proposed model represents the most explanation for the change in the values of the variable of the company in question, with the model's determining factor of $89.96 \%$. The final value of loss was the lowest value of the fourth model, 2.9384. This enables us to rely on the results of the proposed fourth model in interpreting the relationship between the respective profitability of the company in question and the proposed explanatory variables. Therefore, the proposed transcendental production function of the Tawuniya will be in the form of:

$$
E P S=-53.0128 K^{1.2416} L^{-51.3857} P R^{28.0167} C L^{-1.976} \cdot e^{-0.001 K+1.797 L-0.0001 P R-0.0001 C L}
$$

\subsubsection{Bupa Cooperative Insurance Company}

The fourth proposed model represents the most explanation for the change in the values of the variable of the company in question, the selection coefficient for the model was $95.101 \%$, and the final value loss was the lowest value of the fourth form, 0.2564 . This confirms the morale of the proposed model, so the proposed transcendental production function of Bupa will be in the form of:

$$
E P S=-17.7559 K^{2.081} L^{-2.742} P R^{0.448} C L^{-0.3675} \cdot e^{-0.0001 K+0.0211 L-0.00024 P R-0.0001 C L}
$$

\subsubsection{Enaya Cooperative Insurance Company}

The fourth proposed model, which relies on the addition of the variable of claims incurred, represents the most explanation for the change in the values of the care insurance company's variable, with the model's determining factor of $85.531 \%$. The value of final loss also amounted to the lowest value of the third model, 3.83. This confirms the morale of the proposed model, so the proposed transcendental production function of Enaya insurance company will be in the form of:

$$
E P S=-50.6368 K^{15.555} L^{-30.974} P R^{0.839} C L^{0.6898} \cdot e^{-0.001 K+0.0211 L-0.00024 P R-0.0001 C L}
$$

\subsubsection{Sanad Cooperative Insurance Company}

The determining factor for the fourth proposed model of the noble production function of Sanad Cooperative insurance Company was $79.994 \%$, which represents the most explanation for the change in the dependent variable, and the final value of loss was the lowest value of the second form, 8.97. This confirms the morale of the proposed model, so the proposed transcendental production function of Sanad Cooperative insurance company will be in the form of:

$$
E P S=-281.35 K^{13.9882} L^{19.53178} P R^{-0.435} C L^{0.1723} \cdot e^{-0.0001 K-0.0001 L-3415 P R-0.0001 C L}
$$

The previous model reflects the existence of a direct moral relationship to capital and work, claims incurred as production elements with the profitability of the company's shares, and an inverse relationship with the net subscribed premium element. It can be said that the increase of the capital element by $1 \%$ 
increases the earnings of the share by $13.988 \%$, the increase of the work item by $1 \%$ increases the earnings of the share by $19.532 \%$, and the increase in the volume of subscribed premiums by $1 \%$ reduces the earnings of the share by $0.435 \%$ and increase the volume of claims incurred by $1 \%$ will increase profitability by $0.1723 \%$. The value of the constant-281.35, which represents other productive factors that affect the earnings of the stock, has reached a negative effect because of a lower value than the correct one. The above is illustrated by the quality of the fourth proposed model for all companies in question, reflecting the positive contribution of both the subscribed premiums and the claims incurred in interpreting the change in the dependent variant of the earnings of the stock.

\section{COMPARING THE RESULTS OF THE PROPOSED MODELS FOR THE PRODUCTION FUNCTIONS}

The selection of the appropriate model for each of the companies in question depends on the extent to which the results are agreed with the common regression model, as well as the agreement on the results and economic trends of these variables, and the explanatory value of the selection factor for the selected models. Table 4 presents the proposed models for each of the production functions that have been studied for each of the respective companies, also Table 4 reflects the values of the proposed function parameters, the loss unction, and the selection coefficient:

Table 4. Shows the comparative results of the proposed production functions and the common regression

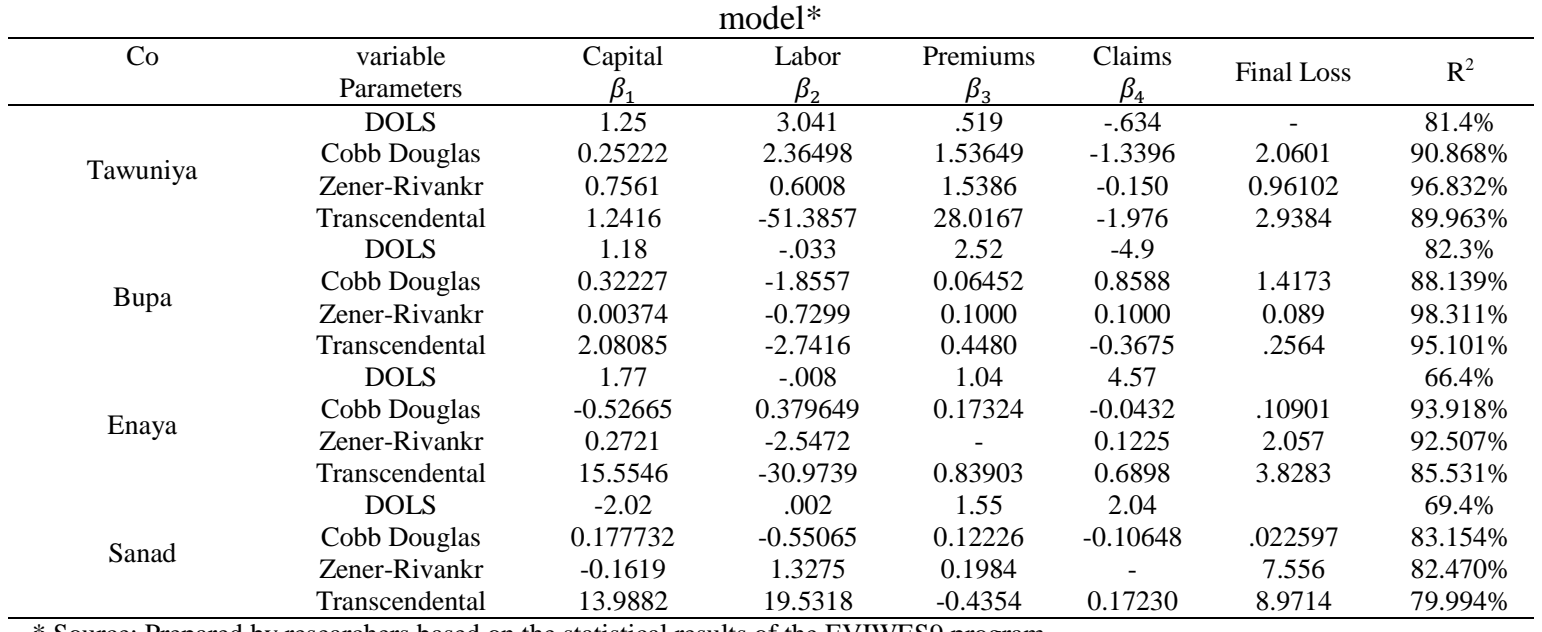

* Source: Prepared by researchers based on the statistical results of the EVIWES9 program.

It is clear from the quantitative examination of the model from the previous table that the ZenerRivanker production function is the most suitable function for Tawuniya and BUPA Collaborative Insurance Companies, and the production function of Cobb-Douglas represents the most suitable functions for the Tawuniya care and Sanad Cooperative Insurance Companies.

\section{CONCLUSION}

The Zener-Rivanker function is the best explanation for the study variables of the cooperative insurance company, as it has the highest coefficient of determination $(96.832 \%)$, it is clear from the proposed production function that to increase the profitability of the stock of the Tawuniya, a future plan should be developed, which would include first developing the volume of premiums collected as a result of being the most contributing factor in increasing the profitability of the company according to the production function. With regard to Bupa for cooperative insurance, the results are consistent with the proposed model of the Zener-Rivanker function, which is the highest coefficient of determination, which amounted to $98.311 \%$ and less final loss (0.089), and the results reflect a direct correlation of both capital and premiums and claims incurred on the profitability shares of the company. The results of Enaya Cooperative Insurance company agreed and the results of the production function of Cobb-Douglas with a coefficient of determination of $93.918 \%$, and the lowest value of final loss reached 0.10901 , and by reviewing the results of the function it can be said that the possibility of reducing the capital element is of high importance in trying to eliminate the losses achieved by the profitability of the company's shares, followed by the importance of trying to increase and raise the efficiency of the company's human energies by increasing the work component, and then trying 
to develop a policy that is based on increasing the size of installments. The results of Sanad Cooperative Insurance Company and Enaya are consistent, which can be explained by the fact that each company achieves losses for most of the study periods, by reviewing the results of Sanad find that they agreed and the production function of Cobb Douglas, with a determining factor of 83.154\%, and final Loss reached 0.22597, reflecting the results some of the indicators that may enable the company to make profits and try to avoid the loss of the shares of the company, where it is clear that Sanad Company suffers from the low efficiency and effectiveness of the work component, which need to reduce it or increase efficiency, then try to increase the capital element which adds more productive capacity Of the company.

\section{REFERENCES}

[1] Md. Moyazzem Hossain and Ajit Kumar Majumder, "On Measurement of Efficiency of Cobb-Douglas Production Function with Additive and Multiplicative Errors," Statistics, Optimization and Information Computing, vol. 3, no. 1, pp. 96-104, 2015.

[2] Dana Hájková, "Cobb-Douglas Production Function: The Case of a Converging Economy," Czech Journal of Economics and Finance, vol. 57, no. 9-10, pp. 465-476, 2006.

[3] Besa Xhaferi, "Production Function of Companies-The Case of Macedonia and Albania," International Journal of Management Sciences, vol. 5, no. 3, pp. 213-221, 2015.

[4] Jan Cadil, Kristyna Vltavska, Igor Krejčí, David Hartman, Marek Brabec, "Aggregate Production Function and Income Identity-Empirical Analysis,” International Journal of Economic Sciences, vol. 6, no. 1, pp. 1-17, 2017.

[5] El-Shawadfy, Khaled, "An Estimation of Cobb-Douglas production function in Egyptian tourism sector," Zagazig University, pp. 1-16, 2000.

[6] Banaeian N., and Zangeneh M., "Estimating Production Function of Walnut Production In Iran Using CobbDouglas Method," Agricultura Tropica ET Subtropica, vol. 44, no. 4, pp. 177-189, 2012.

[7] Shaiara Husain, and Md. Shahidul Islam, "A Test for the Cobb Douglas Production Function in Manufacturing Sector: The Case of Bangladesh," International Journal of Business and Economics Research, vol. 5, no. 5, pp. 149-154, 2016.

[8] Bilel Jarraya, and Abdelfatteh Bouri, "Optimal Production Plan and Profit Efficiency in European Non-Life Insurance Companies," Procedia Economics and Finance, vol. 13, pp. 69-81, 2014.

[9] David L. Debertin, "Agricultural Production Economics," Bibliography: p-Library of Congress Cataloging in Publication data, Second edition, 2012.

[10] Erik Hjalmarsson and Par Osterholm, "Testing for Cointegration Using the Johansen Methodology when Variables are Near-Integrated," International Monetary Fund, pp. 1-19, 2007.

[11] Schubert Katheline, "Macroecnomie comportements," Vuibert, 1996.

[12] Dietmar Lindenberger, "Service production functions," Journal of Economics, vol. 80, no. 2, pp. 127-142, 2003.

[13] Zaman, Gheorghe and Goschin, Zizi and Partachi, Ion and Herteliu, Claudiu, "The Contribution of Labour and Capital to Romania's and Moldova's Economic Growth, Munich Personal RePEc Archive," 2007. [Online]. Available: https://mpra.ub.uni-muenchen.de/88834/MPRA Paper No. 88834.

[14] Eric A. Hanushek, "Education Production Functions," The New Palgrave Dictionary of Economics, 2008.

[15] Romer, “Advanced Macroeconomics," McGraw-Hill Companies, Inc2nd Edition, 2001.

[16] Ben-Gad, M., "Importing Human Capital: Immigration in the Endogenous Growth Model," Central European University Economics Working, no. WP/3, 2003.

[17] Mishra, S. K., “A Brief History of Production Functions," Munich Personal RePEc Archive, 2007.

[18] Border K. C., "On the Cobb-Douglas Production Function," Caltech-Division of the Humanities and Social Sciences, pp. 1-2, 2004.

[19] Francesca D. Auria, and Cecile Denis, "The production function methodology for calculating potential growth rates and output gaps," Publications Office of the European Union, vol. 420, pp. 1-105, 2010.

[20] Jesus Felipe, et al., "The Estimation of the Cobb-Douglas Function," Eastern Economic Journal, vol. 31, no. 3, pp. 427-445, 2005.

[21] Pol Antras, "I s the U.S. Aggregate Production Function Cobb-Douglas? New Estimates of the Elasticity of Substitution," Harvard University, Journals in Macroeconomics, vol. 4, no. 1, pp. 1-34, 2004.

[22] Brooks, Chris, "Introductory econometrics for finance," Second ed., Cambridge university, New York, 2008.

[23] Yan Xin and Gang Su., Xiao, "Linear Regression Analysis Theory and Computing," world scientific, 2009.

[24] Bo-Sjo, "Testing for Unit Roots and Cointegration," 2008. [Online]. Available: https://www.iei.liu.se/nek/ ekonometrisk- teori -7-5-p... / dfdistab7b.pdf.

[25] Peter Almstrom, "Profitability analysis based on production improvements in the electronics manufacturing industry," 2011. [Online]. Available: https://www.researchgate.net/publication/292931584.

[26] Sala and Wong, "Macroeconomic Management Programs and Policies," IMF, Washington, 2002. 